Proc. Indian Acad. Sci. (Earth Planet. Sci.), Vol. 90, Number 1, March 1981, pp. 105-110. (C) Printed in India.

\title{
A simulation technique for the determination of atmospheric water content with Bhaskara satellite microwave radiometer (SAMIR)
}

\author{
P C PANDEY, A K SHARMA and B S GOHIL \\ Motoorology Division, Spaco Applications Centre, Ahmedabad 380053, India \\ MS recoived 6 September 1980; revised 20 December 1980
}

\begin{abstract}
A simulation technique has been developed to estimate the integrated atmospheric water content over oceans using the 19.35 and $22.235 \mathrm{GHz}$ brightness tomperature data from satelite microwave radiometer (SAMIR) on board the Indian satellite Bhaskara. The results obtained have bean compared with those from linear statistical regression and empirical methods as well as from the nearest radiosonde observations. Based on the simulation method, a map of total precipitable water for some of the Bhaskara passes in July 1980 over Bay of Bengal is given. The possible applications of such maps in the study of Indian summar monsoon and boundary layer characteristics have been pointed out.
\end{abstract}

Keywords. Simulation technique; Bhaskara SAMUR; atmospheric water content; brightness temperature.

\section{Introduction}

The total water vapour and liquid water contents over oceans have been derived by Staelin et al (1976) and Grody (1976) using data from Nimbus E microwave spectrometer. Basharinov et al (1969) and Gurvich and Demin (1970) have derived these quantities using Cosmos-243 microwave radiometer data.

In the present paper, the authors have developed a simulation technique to derive total water content over oceans using data from the microwave radiometer (SAMIR) on board the Indian satellite Bhaskara.

SAMIR is a two-frequency radiometer, one at $19 \cdot 35 \mathrm{GHz}$ and the other at $22.235 \mathrm{GHz}$. The ground resolution at nadir is $125 \mathrm{~km}$ and $200 \mathrm{~km}$ circle respectively for 19 and $22 \mathrm{GHz}$ frequencies. The temperature resolution of either channel is about $1^{\circ} \mathrm{K}$. The instrument collects data at $+5 \cdot 6,+2 \cdot 8$, $-2 \cdot 8,-5 \cdot 6^{\circ}$ from nadir along the subsatellite track at $19 \cdot 35 \mathrm{GHz}$ and at $+11 \cdot 2,+2 \cdot 8,-2 \cdot 8,-11 \cdot 6^{\circ}$ at $22 \cdot 235 \mathrm{GHz}$. The data at $2 \cdot 8^{\circ}$ look angle have been used in the present analysis. The details are described by Pandey et al (1980).

The effect of ocean surface roughness was taken into account using an empirical expression suggested by Hollinger et al (1975), wherever information on ocean surface wind was known; otherwise the wind effect was not included. 
Possible applications of total precipitable water and the maps generated therefrom for synoptic analysis, boundary layer studies and computation of fluxes of total precipitable water in the study of Indian summer monsoon have been pointed out.

\section{Mathematical developments}

For a nonscattering atmosphere in local thermodynamic equilibrium, the radiative transfer equation describing the intensity of radiation omerging from the atmosphere can be written in terms of brightness temperature (equivalent black body) as

$$
\begin{aligned}
T_{B}(\nu)= & \int_{0}^{H} T(z) \frac{\partial \tau_{\nu}(Z, H)}{\partial Z} d Z+\tau_{\nu}(0, H)\left[\epsilon_{2}(v) T_{0}+\left(1-\epsilon_{0}(\nu)\right)\right] \\
& \times \int_{H}^{0} T(z) \frac{\partial \tau_{\nu}(0, z)}{\partial z} d z .
\end{aligned}
$$

The three terms on the right side of equation (1) represents (a) the upward emission by the atmosphere, $(b)$ emission by the surface attenuated by the intervening atmosphere and (c) downward emission of the atmosphero that is reflected by the surface and attenuated in its upwelling path by the intervening atmosphere.

The satellite altitude, emissivity and sea surface temperature are designated by $H, \epsilon_{,}(v)$ and $T_{s}$.

Equation (1) can be rewritten in an alternate form as follows :

$$
T_{B}(v)=T_{s}\left[a(v)-\beta(v) \tau^{2}(0, H)\left(1-\epsilon_{s}(v)\right],\right.
$$

where $a(v)=1+\int_{0}^{t}\left(1-\tau_{v}(Z, H)\right) \frac{1}{T_{0}} \frac{\partial T(Z)}{\partial Z} d Z$,

$$
\beta(v)=1-\int_{0}^{H}\left(1-\tau_{\nu}(Z, H)\right) \frac{1}{T_{,} \tau_{p}(Z, H)} \frac{\partial T(Z)}{\partial Z} d Z
$$

using atmospheric data, the expressions for $a(v)$ and $\beta(v) \tau,(0, H)$ could be written in terms of total transmittances.

$$
\begin{aligned}
& a(v)=A+B \tau+C \tau^{2} \\
& \beta(v) \tau^{2}(0, H)=D+E \tau+F \tau^{2} \\
& \tau_{\nu}=\frac{-(B-E r) \pm\left\{(B-E r)^{2}-4(C-F r)\left(A-D r-\left[T_{B}(v) / T_{\ell}\right]\right)\right\}^{2}}{2(C-F r)}
\end{aligned}
$$

where $r=1-\epsilon_{0}(v)$.

The constants, $A, B, C, D, E$ and $F$ are determined using 300 , atmospheric simulations with both clear and cloudy atmospheres. The solution of (2) after 
Table 1. Values of the constants in the regression equations (5) and (6).

\begin{tabular}{lcccccccc}
\hline $\begin{array}{c}\text { Frequency } \\
\text { GHz }\end{array}$ & $A$ & $B$ & $C$ & $\begin{array}{c}\mathrm{rms} \\
\text { error }\end{array}$ & $D$ & $E$ & $F$ & $\begin{array}{c}\text { rms } \\
\text { orror }\end{array}$ \\
\hline$v_{1}=19.35$ & 0.5037 & 1.1106 & -0.6289 & 0.0029 & 0.0272 & -0.0021 & 0.9726 & 0.0005 \\
$v_{1}=22.235$ & 0.8611 & 0.2679 & -0.1384 & 0.0012 & -0.0023 & 0.0674 & 0.933 & 0.0009 \\
\hline
\end{tabular}

substituting (5) and (6) is given in terms of brightness temperature by (6a). The clouds with liquid water contents in the multiple of $0.15 \mathrm{~g} \mathrm{~m}^{-3}$ with maximum $0.60 \mathrm{~g} \mathrm{~m}^{-3}$ were used in the simulation. The base and top of the cloud were also varied $(1 \cdot 5-5 \cdot 5 \mathrm{~km})$. The constants in the regression equations (5) and (6) and the r.m.s. error in the determination of $a(v)$ and $\beta(v) \tau_{v}^{2}(0, H)$ using exact expressions [equations (3)-(4) 1 are given in table 1.

In the case of cloudy atmosphere, the main absorbers of the electromagnetic radiation are water vapour, and oxygen molecule in gaseous phase and liquid water in the form of clouds. The total transmittance can therefore be written as

$$
\tau_{\nu}=\tau_{\mathrm{cl}}(v) \cdot\left(\tau_{\mathrm{H}, \mathrm{O}}(v) \cdot \tau_{\mathrm{oz}}(v)\right)
$$

The relation between bracketted parts of (7), for the two frequencies 19 and $22 \cdot 235 \mathrm{GHz}$, obtained from atmospheric calculations, yielded the following regression equation:

$$
\tau_{\mathrm{Bg}}(19) \tau_{\mathrm{O}}(19)=a \tau_{\mathrm{F} \rho \mathrm{O}}(22) \tau_{\mathrm{os}}(22)+b
$$

where $a=0.3846$ and $b=0.6155$. The transmittance due to cloud is given by

$$
\tau_{\mathrm{cl}}(v)=\exp \left(-k v^{2} Q\right)
$$

where $v$ is in $\mathrm{GHz}$ and the parameter $k$ is given by

$$
k=1 \cdot 11 \times 10\left[0.0122\left(201-T_{c}\right)-1\right]
$$

where $T_{\mathrm{cl}}=$ cloud temperature in degree K. From (9), the transmittances due to cloud at $19 \cdot 35$ and $22 \cdot 235 \mathrm{GHz}$ frequencies are related as

$$
\tau_{\mathrm{el}}\left(v_{2}\right)=\left(a^{\prime}+b^{\prime} Q+c^{\prime} Q^{2}\right) \tau_{\mathrm{cl}}\left(v_{1}\right)
$$

where the constants are given as $a^{\prime}=1.0, b^{\prime}=-0.0318, c^{\prime}=0.0005$.

Equations $(7)-(10)$ can be solved in a straightforward manner to yield $\tau(22)$ and $\tau_{\text {uro }}(22) \tau_{\text {os }}(22)$.

From (7), (8) and (10), and using atmospheric simulations it is possible to derive the following expressions for total atmospheric water vapour and liquid water contents :

$$
W=19 \cdot 2676\left(1-1.0365 \tau_{\mathrm{RgO}}(22) \tau_{\mathrm{o}_{9}}(22)\right)
$$

and $\quad Q=7 \cdot 6279\left(1-\frac{\tau(22)}{\tau_{\mathrm{B}, \mathrm{O}}(22) \tau_{\mathrm{o}}(22)}\right)$. 
However, it should be noted that the above procedure requires the values of $T_{\mathrm{cl}} \sim\left(260^{\circ} \mathrm{K}\right.$ in the present calculations), sea surface temperature $\left(T_{8} \sim 300^{\circ} \mathrm{K}\right)$ and the emissivity calculated from Fresnel's formula. The increased emissivity due to wind-generated foams and surface roughness could be accounted using the empirical equation given by Hollinger et al (1975)

$$
\Delta T_{B}=0.134 \triangle W f^{1 / 2}
$$

where $\Delta W$ is in knots ( $>7$ knots) $f$ in GHz, and $\Delta T_{B}$ in degree $\mathrm{K}$.

\section{Results and discassions}

The results of the computation using simulation technique are presented in table 2 along with results obtained from other methods. It is seen that the agreement is satisfactory. The antenna pattern correction has not been taken into account while processing the SAMIR data.

The effect of different atmospheres used in the simulation to derive the coefficients has also been analysed and the results given in table 3 show that all the three regression equations give the values of $W$ and $Q$ and are within about $\pm 5 \%$.

Based on the simulation method discussed earlier, it is possible to map the total water vapour and study its variations along with auxiliary data such as visible and infrared bands. Such types of global maps have been derived by Grody (1978) using the data from a scanning microwave spectrometer (SCAMS) that was flown on Nimbus 6.

Maps for total precipitable water and remotely-sensed sea surface temperature can be used to infer the gross characteristics of the boundary layer over the oceanic regions. This is possible because, on an average, the vertical distribution of water vapour in the atmosphere over the water bodies can be represented with a

Table 2. Comparison of total water vapour content $\left(\mathrm{g} \mathrm{cm}^{-2}\right)$ and liquid watercontent $\left(\mathrm{kg} \mathrm{m}^{-3}\right)$ as dotermined from different methods.

\begin{tabular}{|c|c|c|c|c|c|c|c|c|c|}
\hline \multirow{2}{*}{ Day 1979} & \multirow{2}{*}{$\begin{array}{l}\text { Orbit } \\
\text { No. }\end{array}$} & \multicolumn{2}{|c|}{ Simulation } & \multicolumn{2}{|c|}{ Statistical } & \multicolumn{2}{|c|}{ Empirical } & \multicolumn{2}{|c|}{ Radiosonde } \\
\hline & & $W$ & $Q$ & $\boldsymbol{W}$ & $Q$ & $W$ & $Q$ & $W$ & $Q$ \\
\hline July 6 & 434 & $3 \cdot 50$ & $1 \cdot 1$ & 3.68 & 1.05 & $4 \cdot 39$ & .. & $4 \cdot 4$ & .. \\
\hline July 8 & 464 & $3 \cdot 92$ & $0 \cdot 89$ & $4 \cdot 19$ & 1.03 & $4 \cdot 70$ & .. & $4 \cdot 4$ & .. \\
\hline July 15 & 575 & $4 \cdot 28$ & 0.57 & $4 \cdot 09$ & 0.82 & $4 \cdot 62$ & .. & $4 \cdot 4$ & .. \\
\hline August 1 & 829 & $5 \cdot 04$ & 0.85 & $4 \cdot 70$ & $1 \cdot 12$ & $5 \cdot 07$ & .. & $5 \cdot 3$ & .. \\
\hline August 3 & 860 & $5 \cdot 17$ & 0.60 & 4.58 & 0.94 & $4 \cdot 79$ & .. & $5 \cdot 2$ & .. \\
\hline August 22 & 1149 & $3 \cdot 65$ & 0.56 & $3 \cdot 72$ & 0.73 & $4 \cdot 34$ & .. & $4 \cdot 0$ & .. \\
\hline August 23 & 1164 & $3 \cdot 57$ & 0.63 & 3.75 & 0.78 & $4 \cdot 36$ & .. & $4 \cdot 8$ & .. \\
\hline September 3 & 1327 & $5 \cdot 92$ & $0 \cdot 36$ & $4 \cdot 78$ & 0.84 & $5 \cdot 06$ & .. & .. & .. \\
\hline October 10 & 1812 & $4 \cdot 59$ & $0 \cdot 56$ & $4 \cdot 25$ & 0.84 & $4 \cdot 70$ & .. & .. & .. \\
\hline October 17 & 1998 & $4 \cdot 55$ & $0 \cdot 72$ & $4 \cdot 37$ & 0.97 & $4 \cdot 81$ & .. & .. & .. \\
\hline October 21 & 2057 & 2.99 & 0.67 & $3 \cdot 46$ & 0.74 & $4 \cdot 16$ & .. & .. & .. \\
\hline
\end{tabular}


Tabłe 3. Total water vapour $\left(\mathrm{g} \mathrm{cm}^{-2}\right)$ and liquid water contents $\left(\mathrm{kg} \mathrm{m}^{-2}\right)$ determined from simulation method using throe different atmospheric conditions for simulation.

\begin{tabular}{|c|c|c|c|c|c|c|c|c|c|c|c|}
\hline \multirow{2}{*}{ Day 1979} & \multirow[t]{2}{*}{$\begin{array}{c}\text { Orbit } \\
\text { No. }\end{array}$} & \multirow[t]{2}{*}{$\begin{array}{l}\text { Lati- } \\
\text { tude }\end{array}$} & \multirow[t]{2}{*}{$\begin{array}{l}\text { Longi- } \\
\text { tude }\end{array}$} & \multirow[t]{2}{*}{$\begin{array}{c}T_{B}(19) \\
\left({ }^{\circ} \mathrm{K}\right)\end{array}$} & \multirow[t]{2}{*}{$\begin{array}{l}T_{B}(22) \\
\left({ }^{\circ} \mathrm{K}\right)\end{array}$} & \multicolumn{2}{|c|}{$\begin{array}{c}1 \mathrm{st} \\
\text { regression }\end{array}$} & \multicolumn{2}{|c|}{$\begin{array}{l}\text { 2nd } \\
\text { regression }\end{array}$} & \multicolumn{2}{|c|}{$\begin{array}{l}\text { 3rd } \\
\text { regression }\end{array}$} \\
\hline & & & & & & $W$ & $Q$ & $W$ & $Q$ & $W$ & $Q$ \\
\hline July 8 & 464 & $07-42$ & $72-33$ & $167 \cdot 8$ & $209 \cdot 4$ & $3 \cdot 90$ & c. 88 & $3 \cdot 99$ & 0.86 & $3 \cdot 89$ & $0 \cdot 88$ \\
\hline July 15 & 575 & $10-55$ & $90-11$ & $159 \cdot 8$ & $206 \cdot 2$ & $4 \cdot 28$ & 0.57 & $4 \cdot 32$ & 0.56 & $4 \cdot 27$ & 0.57 \\
\hline August 1 & 829 & $12-42$ & $73-02$ & $172 \cdot 0$ & $218 \cdot 6$ & $5 \cdot 04$ & 0.84 & $5 \cdot 10$ & $0 \cdot 81$ & $5 \cdot 07$ & 0.83 \\
\hline August 3 & 860 & $16-08$ & $70-36$ & $165 \cdot 3$ & $215 \cdot 3$ & $5 \cdot 17$ & 0.60 & $5 \cdot 21$ & $0 \cdot 58$ & $5 \cdot 21$ & 0.59 \\
\hline August 22 & 1149 & $17-05$ & $6 a_{14}$ & $156 \cdot \dot{0}$ & $199 \cdot 4$ & 3.65 & 0.56 & $3 \cdot 68$ & 0.55 & $3 \cdot 61$ & 0.57 \\
\hline August 23 & 1164 & $07-23$ & $74-19$ & $157 \cdot 8$ & $200 \cdot 2$ & $3 \cdot 57$ & 0.63 & $3 \cdot 62$ & 0.62 & $3 \cdot 54$ & 0.64 \\
\hline September 1 & 1297 & $23-20$ & $87-70$ & $169 \cdot 0$ & $218 \times 0$ & $5 \cdot 24$ & 0.71 & $5 \cdot 30$ & $0 \cdot 68$ & $5 \cdot 30$ & 0.69 \\
\hline September 3 & 1327 & $21-32$ & $83-35$ & $162 \cdot 0$ & $218 \cdot 0$ & $5 \cdot 92$ & $0 \cdot 36$ & $5 \cdot 94$ & $0 \cdot 35$ & 5.99 & 0.34 \\
\hline October 5 & 1812 & $14-53$ & $80-51$ & $161 \cdot 0$ & $209 \cdot 0$ & 4.59 & 0.56 & $4 \cdot 63$ & 0.54 & $4 \cdot 60$ & 0.56 \\
\hline October 17 & 1998 & $07-20$ & $80-31$ & $166 \cdot 0$ & $212 \cdot 0$ & $4 \cdot 55$ & 0.72 & $4 \cdot 61$ & $0 \cdot 70$ & $4 \cdot 56$ & 0.72 \\
\hline October 21 & 2057 & $18-10$ & $91-46$ & $156 \cdot 0$ & $195 \cdot 0$ & $2 \cdot 30$ & 0.67 & $3 \cdot 04$ & 0.66 & $2 \cdot 94$ & 0.68 \\
\hline November 7 & 2311 & $08-01$ & $84-35$ & $193 \cdot 0$ & $219 \cdot 0$ & $2 \cdot 04$ & $2 \cdot 03$ & $2 \cdot 06$ & $2 \cdot 03$ & 1.93 & $2 \cdot 09$ \\
\hline November 14 & 2423 & $11-31$ & $82-42$ & $173 \cdot 0$ & $219 \cdot 0$ & $4 \cdot 99$ & 0.88 & $5 \cdot 05$ & 0.86 & $5 \cdot 03$ & 0.87 \\
\hline November 22 & 2542 & $09-54$ & $88-53$ & $177 \cdot 0$ & $223 \cdot 0$ & $5 \cdot 27$ & 0.98 & $5 \cdot 34$ & 0.95 & $5 \cdot 35$ & 0.96 \\
\hline
\end{tabular}

simple model. Then some average value of precipitable water $W$ can be associated to a given surface temperature. The departure of the measured $W$ from the corresponding $W$ relates to the atmospheric stratification in the boundary layer. For instance when $W>\bar{W}$, convective conditions (ITCZ) are present and when $W<\bar{W}$ stable condition prevails (Prabhakara et al 1978).

In addition, such types of maps could as well be used for calculating fluxes of total precipitable water affecting the monsoon. Ghosh et al (1978) have studied the Indian summer monsoon based on the conventional data alone but it is now conceivable to utilise satellite data for similar studies.

\section{Acknowledgements}

The authors are grateful to Dr T A Hariharan, Meteorology Division, for constant encouragement and useful suggestions. Thanks are also due to Prof Yash $\mathrm{Pal}$ for his keen interest in the present investigation. The authors are grateful to Dr Norman Grody, NOAA, USA for many useful suggestions through correspondence. The authors acknowledge the benefit of their discussions with Drs P S Desai, M S Narayanan and V K Agarwal of the Meteorology Division. 


\section{References}

Basharinov A E, Gurvich A S and Yegerov S T 1969 Dokl. Akad. Nauk, USSR 1881273

Gurvich A S and Demin V V 1970 Atm. Oceanic Phys. 6771

Grody N C 1976 IEEE Trans. Ant. Prop. AP-24 155

Grody N C 1978 J. Geophys. Res. 831857

Ghosh S K, Pant M C and Dewan B N 1978 Tellus 30117

Hollinger James $P$, Lerner $R \quad M$ and Wisler $M$ M 1975 An investigation of the remote determination of sea surface temperature using microwave radiomotry, NRL Memorandum Report No. 3159

Pandey P C, Sharma A K and Gohil B S 1981 Mausam 3217

Prabhakara C, Dalu G, Lo R and Nath R 1978 Inference of boundary layer structuro over the oceans from satellite infrared measurements, NASA Tech Memo 79653

Staelin D H, Kunzi K P, Detty John R L, Poon R K L, Wilcox R W and Waters J W 1976 J. App'. Meteor. 151204 